J. Lake Sci.(湖泊科学), 2017, 29(2): 467-479

DOI 10. 18307/2017. 0223

(C) 2017 by Journal of Lake Sciences

\title{
巴丹吉林沙漠湖泊水分补给机制的模拟一一以苏木吉林湖区为例”
}

\author{
张 竞 ${ }^{1,2}$, 王旭升 ${ }^{2}$, 胡晓农 ${ }^{2}$, 卢会婷 ${ }^{2}$, 马 震 1 \\ (1: 中国地质调查局天津地质调查中心,天津 300170) \\ (2: 河北省地质调查院,石家庄 050081)
}

\begin{abstract}
摘 要: 巴丹吉林沙漠气候干旱, 蒸发强烈, 与之形成鲜明对比的是沙漠腹地湖泊群的长久不衰, 目前对于湖泊水分的补 给来源仍存在争议. 本文以水量均衡为基础, 在苏木吉林湖区开展了降水、蒸发及湖水位和地下水位的动态监测, 结合已 有的水文地质资料建立地下水流动三维模型,重现湖区地下水位的季节动态变化,并基于模型进行水均衡分析. 结果表 明: 苏木吉林湖区降水人渗补给量不足以平衡湖泊蒸发量, 湖泊需要深层承压水的越流补给; 湖水位和地下水位均呈现 正弦曲线形态, 11 月最低, 4 月达到峰值, 水位变幅分别为 22 和 $18 \mathrm{~cm}$; 湖区地下水多年平均总补给量为 $11620 \mathrm{~m}^{3} / \mathrm{d}$, 其 中降水和承压水越流分别约占 $13 \%$ 和 $87 \%$, 降水补给量夏季高、冬季低, 承压水越流补给量季节变化不明显; 承压水越流 补给量可能主要来源于沙漠周边山区降水, 未发现明显的水量亏空需要断裂导水来弥补. 研究结果为巴丹吉林沙漠地下 水资源分析及合理利用提供科学依据.
\end{abstract}

关键词 : 巴丹吉林沙漠;湖泊;地下水模型;水均衡;水文地质;苏木吉林湖区

\section{Research on the recharge of the lakes in the Badain Jaran Desert: Simulation study in the Sumu Jaran lakes area}

ZHANG Jing ${ }^{1,2}$, WANG Xusheng ${ }^{2}$, HU Xiaonong ${ }^{2}$, LU Huiting ${ }^{2}$ \& MA Zhen

(1: Tianjin Centre, China Geological Survey, Tianjin 300170, P.R.China)

(2: Hebei Institute of Geological Survey, Shijiazhuang 050081, P.R.China)

\begin{abstract}
The Badain Jaran Desert was located at the northwest inland of China with drought and intensive evaporation. In stark contrast, there were dozens of permanent lakes inside the desert hinterland. Water recharge of the lakes in the Badain Jaran Desert has always been controversial. Based on water balance algorithm, this paper investigated the water recharging mechanism of the lakes. Dynamic observations of precipitation, evaporation, lake level and groundwater level were conducted in the Sumu Jaran lakes area. Based on the data analysis, a 3D model of groundwater was set up to reconstruct the seasonal dynamic characteristics of the groundwater level in the lakes area, and the water balance analysis was carried out. The results indicated that the precipitation wasn't sufficient to meet the water loss via evaporation, and leakage of deep confined water was important to maintain the lakes. Both the groundwater level and the lake level showed as a sine curve, and the changing range was 18 and $22 \mathrm{~cm}$, respectively. The maximum and minimum value of groundwater level and lake level appeared in April and November, respectively. The average recharge rate of the Sumu Jaran lakes for many years was approximately $11620 \mathrm{~m}^{3} / \mathrm{d}$, to which the rainfall and leakage of the deep confined water contributed $13 \%$ and $87 \%$, respectively. The former was high in summer and low in winter, while the seasonal variation of the latter was not obvious. The deep confined water, ultimately, was probably formed with rainfall in the mountain areas around the southeast Badain Jaran Desert. No obvious water deficit needs to be covered by the groundwater that is transported to fractured zone from the remote area. The results can provide scientific gist for the rational use of groundwater in the Badain Jaran Desert. Keywords: Badain Jaran Desert; lakes; groundwater model; water balance; hydrogeology; Sumu Jaran lakes
\end{abstract}

巴丹吉林沙漠位于我国西北部的干旱半干旱地区, 在沙漠东南部腹地星罗棋布地点缀着 100 多个湖

* 国家自然科学基金重大研究计划项目 (91125024) 和核设施退役及放射性废物治理项目(科工二司 [2013]727 号) 联合资助.2016-01-12 收稿;2016-05-29 收修改稿.张竞( 1986 ), 男,博士;E-mail:550539163@ qq.com. 
泊, 其中常年有水的湖泊 70 多个 ${ }^{1]}$, 形成了世界上独一无二的沙山一湖泊景观. 沙漠与外部并无地表水量 交换, 多年平均降水量不足 $100 \mathrm{~mm}$, 水面蒸发量却高达 $3000 \sim 4000 \mathrm{~mm}^{[2-4]}$, 水分收支悬殊, 湖泊长久不衰的 原因给学术界带来了疑惑. 长期以来, 研究人员在巴丹吉林沙漠开展了大量的研究并获得了许多关于湖泊 水分补给的认知,但到目前为止仍存在争议 ${ }^{[5]}$.

湖区当地的降水是否足以平衡湖泊蒸发量? 这是第一个分歧点. 王涛粗略地估算了单个湖泊可以接收 的降水量和湖面蒸发量, 认为当地降水量足够抵消掉蒸发量而维持湖泊水位稳定 ${ }^{[6]}$. Dong 等发现湖泊多呈 东西向的条带状分布, 推测这种条带状可能是向斜发育的位置, 降雨从南北两侧流到向斜核部以向斜泉的 形式补给湖泊, 估算湖泊群接受了向斜南北两侧大约 $6500 \mathrm{~km}^{2}$ 面积上的降水, 认为这些降水足够抵消掉沙 漠中所有湖泊的蒸发 ${ }^{[7]}$. 这些估算较粗粘, 且忽略了降水人渗系数, 会造成估算的降水补给量偏大. Ma 和 Gates 等学者虽然也认为湖泊水源来自降水, 但他们基于氯离子平衡法估算的现代降水人渗补给量仅为 $1.3 \sim 1.4 \mathrm{~mm} / \mathrm{a}$, 降水人渗系数仅为 $1.5 \% \sim 1.7 \%{ }^{[8-13]}$, 并认为巴丹吉林沙漠的地下水和湖水是远古湿润历史 时期遗留下来的降水.

相比之下, 更多的学者认为湖区的降水量不足以支撑湖泊, 湖水存在其它的补给源, 关于该补给源的位 置则存在激烈的争论. 丁宏伟等 ${ }^{[14]}$ 研究发现了黑河下游的盈余地下水量与巴丹吉林沙漠的亏空地下水量 呈现惊人的相似, 结合水化学证据提出黑河水沿阿尔金断裂地表破碎带自西向东补给至巴丹吉林沙漠湖泊 群的观点. 仵彦卿等 ${ }^{[15-16]}$ 通过浅层物探发现, 在沙漠西北部的哨马营地区发育一些断裂, 埋深在 $100 \mathrm{~m}$ 以 上,推测这些断裂可能将鼎新盆地的黑河水引人古日乃湖并继续向沙漠东南部腹地的湖泊群补给. $1960 \mathrm{~s}-$ 1980s, 通过一些基本的水文地质调查, 地质研究者一般认为沙漠周边的砂岩和花岗岩出露区对巴丹吉林沙 漠地下水具有侧向补给作用, 但他们没有论证这种侧向来水是否能够与沙漠湖泊的耗水量平衡 ${ }^{[17]}$. 同位素 研究对湖泊水源的定位更加遥远, 陈建生等用気氧同位素理论阐述了巴丹吉林沙漠地下水与祁连山和青藏 高原水体的关系 ${ }^{[4,18-19]}$, 提出沙漠地下水和湖水由祁连山乃至青藏高原的降水所补给的观点 ${ }^{[18-22]}$, 为了解决 水分输运问题, 认为雪水融化后会渗人到祁连山深部的大断裂系统以及阿尔金断裂系统中, 这些断裂疏导 地下水补给了沙漠地下水. 许多学者对该观点提出了强烈的质疑 ${ }^{[10,13,23-27]}$. 刘建刚 ${ }^{[28]}$ 认为巴丹吉林沙漠湖 泊水由于蒸发作用强烈, $\delta \mathrm{D}$ 和 $\delta^{18} \mathrm{O}$ 值均偏离了大气降水线, 不能直接利用它们与降水线和蒸发线的关系确 定补给水源. 张虎才等基于对祁连山地形和阿尔金断裂高程的分析质疑了阿尔金断裂作为断裂导水通道的 可能性, 并认为陈建生对 Sr 同位素比值的解释是错误的 ${ }^{[25]}$. Zhao 等 ${ }^{[23]}$ 认为陈建生等的理论中同位素取样 的数量还远远不够, 他们同样分析了巴丹吉林沙漠和附近祁连山以及黑河上中下游 300 多个地下水、河水 和降水样品, 结果并不支持陈建生等的理论.

前人学者从不同角度提供了沙漠湖泊水分补给的证据, 笔者认为, 应当从空间和时间两方面对已有的 研究进行准确定位. 首先, 根据水文地质以及地下水循环的基本原理, 对于水源的位置没有必要做出非此即 彼的排他性判断, 巴丹吉林沙漠位于构造活动强烈的地带 ${ }^{[29]}$, 水文地质条件比较复杂, 其地下水的补给方式 可以具有多样性, 仅凭借某一方面的证据断定湖泊水分来源于某处是片面的. 其次, 对于降水补给发生在古 代还是现代, 应该认为地下水循环是个连续不断的过程, 在地质历史上补给量的变化只有强弱之分而非有 或无的差别, 补给强的时期地下水位抬升, 补给弱的时期地下水位下降, 并在气候较为稳定的情况下最终达 到某种平衡状态, 因此, 我们需要回答的是现今的状态是否已经达到补给与排泄的平衡态, 而不是判断地下 水有多古老.

湖泊的水源问题归根结底是一个水均衡问题, 即哪些补给源具有主要作用、哪些补给源的贡献几乎可 以忽略不计, 不论用任何研究方法提出的水分补给学说, 都必须经得起水均衡的验证. 但是, 受限于艰苦的 自然条件, 沙漠腹地一直未能开展水均衡要素的系统监测, 目前尚无湖泊水均衡方面的专题研究, 仅有少数 学者进行了粗糙的估算 ${ }^{[4,6-7,14]}$, 湖泊水分补给和排泄的均衡仍然不清楚.

本研究以水量均衡为基础, 选取巴丹吉林沙漠东南部湖泊群中的苏木巴润吉林湖 (下文简称南湖) 和苏 木吉林湖 (下文简称北湖) 为研究对象, 开展了小流域尺度的气象和水位监测, 获取了盐湖的真实蒸发量及 湖泊水位的季节动态变化, 在收集已有水文地质资料的基础上, 通过地下水建模重现湖区地下水流场的季 节动态变化, 借助该模型进行水均衡分析, 定量揭示湖泊水分的补给机制. 


\section{1 研究区概况}

巴丹吉林沙漠 $\left(39^{\circ} 30^{\prime} \sim 42^{\circ} 0^{\prime} \mathrm{N}, 98^{\circ} 30^{\prime} \sim 104^{\circ} 0^{\prime} \mathrm{E}\right.$ ) 位于中国内蒙古阿拉善高原西部, 大地构造上属于阿 拉善地块, 地质历史时期存在强烈的岩浆活动, 古生代及元古代地层受到花岗岩侵入的影响而支离破碎, 与 花岗岩一起形成山体隆起, 而二叠系石炭系形成盆地, 发育巨厚的浅海陆棚相和碳酸盐台地相沉积, 中生代 表现为一系列的断陷活动,形成了较大范围的陆相沉积, 伴随少量火山活动, 巨厚的白严系砂岩分布在断陷 盆地中. 新生代以来研究区基本没有岩浆活动. 阿拉善地块内部的新构造运动并不显著, 但也可能发育了一 些伸展和走滑构造 ${ }^{[29]}$. 沙漠面积 $4.9 \times 10^{4} \mathrm{~km}^{2}$, 是我国第二大沙漠 ${ }^{[6]}$, 地势上总体呈现东南高、西北低的特 点. 沙漠东南部有高大的复合型沙山, 相对高度一般为 $200 \sim 300 \mathrm{~m}$, 最高超过 $400 \mathrm{~m}$. 沙山之间的洼地分布大 量的常年积水湖泊, 湖泊周边多有下降泉分布, 湖底部有上升泉出露 ${ }^{[30]}$, 这些湖泊中面积大于 $1 \mathrm{~km}^{2}$ 的屈指 可数, 以诺尔图、苏木巴润吉林、音德尔图、呼和吉林、车日格勒等湖为代表, 其中诺尔图面积最大, 可达 1.5 $\mathrm{km}^{2}$, 最大水深 $16 \mathrm{~m}^{[31]}$, 其余大部分湖泊面积都不到 $0.2 \mathrm{~km}^{2}$, 水深不及 $2 \mathrm{~m}^{[32]}$. 本次研究选取的苏木吉林湖 区 (39 $\left.46^{\prime} 4^{\prime \prime} \sim 39^{\circ} 50^{\prime} 0^{\prime \prime} \mathrm{N}, 102^{\circ} 24^{\prime} 15^{\prime \prime} \sim 102^{\circ} 27^{\prime} 17^{\prime \prime} \mathrm{E}\right)$ 湖泊位于低洼地带, 周围被明显的沙山分水岭圈闭形成 局部流域 (图 1). 根据 $30 \mathrm{~m}$ 分辨率的 ASTER G-DEM 数据生成的地形等高线确定的流域面积为 $21.98 \mathrm{~km}^{2}$, 海拔 1179 1567 m, 南北长约 $7300 \mathrm{~m}$, 东西长约 $5600 \mathrm{~m}$. 南湖面积 $1.22 \mathrm{~km}^{2}$, 最大深度超过 $10 \mathrm{~m}$; 北湖面积 $0.61 \mathrm{~km}^{2}$, 平均深度小于 $10 \mathrm{~m}$, 最大深度不详 ${ }^{[33]}$. 根据沙漠周边的气象站, 降水量分布存在空间差异, 东南部 可达 90 115 mm, 西北部则不足 $50 \mathrm{~mm}^{[33]}$.

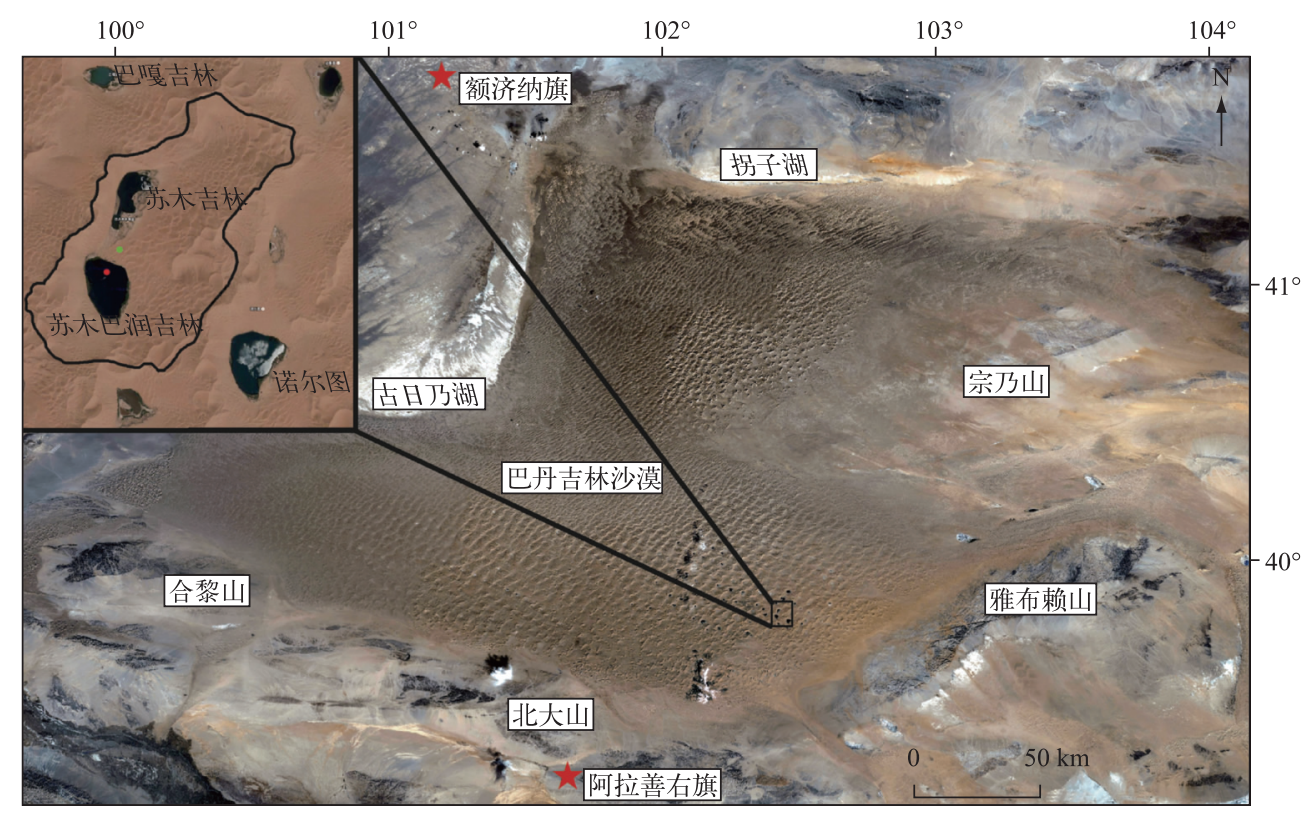

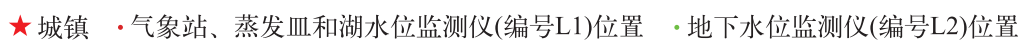
小图中封闭黑线是由Aster G-Dem数据得到的苏木吉林湖区地表分水岭

图 1 巴丹吉林沙漠及苏木吉林湖区遥感

Fig.1 Remote sensing image of the Badain Jaran Desert and Sumu Jaran lakes

\section{2 数据}

水位的动态变化是水均衡状态的重要指标, 也是模拟研究的验证依据. 在本次研究之前, 巴丹吉林沙漠 内部尚没有地下水位的长期监测数据, 为此, 本课题组分别在南湖和南湖北岸安装了 2 个 MiniDiver( 水压水 温传感器), 其中监测南湖水位的 MiniDiver 固定在桥腿上, 编号 L1; 监测地下水位的 MiniDiver 安装在湖岸 
上的监测孔内, 编号 $\mathrm{L} 2$, 孔深 $16 \mathrm{~m}$, 监测频率为 $1 \mathrm{~h}$ (图 1).

降水、蒸发及湖水位和地下水位的监测周期均为一年,从 2012 年 9 月 1 日至 2013 年 8 月 31 日.

\section{1 湖区降水和蒸发}

降水和蒸发作为已知的地下水补给和排泄途径, 其量的确定是判断湖泊水源的重要依据. 距离苏木吉 林湖区最近的气象站位于阿拉善右旗(距离约 $80 \mathrm{~km}$, 图 1), 该站积累了 1978-2000 年以来的气象数据, 对 本次研究具有重要的利用价值. 阿拉善右旗多年平均降水量 $115.8 \mathrm{~mm}$, 多年平均蒸发量 $3452 \mathrm{~mm}^{[34]}$, 两者均 呈现季节性动态变化且变化趋势基本一致, 二者最低值均出现在 1 月, 降水最高值出现在 8 月, 蒸发略早, 出 现在 7 月 (为方便与本次监测数据作对比, 时间轴设为 9 月至次年 8 月, 图 2). 沙漠内部的气象监测开展较 晚, 距今仅 4 5 年的历史. 王乃昂等 ${ }^{[35]}$ 在苏木吉林湖区的监测表明沙漠腹地与阿拉善右旗的降水在季节分 布上有较好的一致性, 但年降水量少于阿拉善右旗且年际变化明显, 如 2010 年降水量约 $104.8 \mathrm{~mm}, 2011$ 年 则为 $75.3 \mathrm{~mm}$. 蒸发方面, 马宁 ${ }^{[36]}$ 利用浴度相关系统观测数据推测的音德尔图湖 (位于苏木吉林湖区以北约 $5 \mathrm{~km}$ ) 2012 年 3 月 25 日-9 月 10 日的湖面平均日蒸发量为 $5.3 \mathrm{~mm}$, 全年蒸发量小于 $1939.8 \mathrm{~mm}$; 杨小平用 改进的适合沙漠地区的彭曼公式计算的湖面蒸发量为 $1040 \mathrm{~mm}^{[37]}$, 这两组蒸发结果远小于阿拉善右旗气象 站给出的多年平均蒸发量 (3452 mm). 综上所述, 苏木吉林湖区近几年的降水和蒸发规律与阿拉善右旗存 在不同程度的差异, 因此需要补充监测. 鉴于此, 课题组于 2012 年 9 月在南湖建立了自动气象站, 监测气 温、降水量和风速等气候要素, 气象站旁装置了 E-601 型蒸发血, 并安装 MiniDiver 用以监测湖泊水面蒸发 量, 同时在附近安装了 BaroDiver (气压气温传感器), 用于监测大气压动态, 以便对 MiniDiver 进行校正. 气象 站和蒸发血均安装于苏木吉林南湖湖心位置, 蒸发血内的水取自湖水, 每月向蒸发血中加人淡水以维持盐 度的稳定.

2012 年 9 月至 2013 年 8 月, 湖区全年降水量为 $163.6 \mathrm{~mm}$, 与阿拉善右旗多年平均值相比高出 $41 \%$, 在 季节分配上呈夏季高、冬季低, 但变化并不均匀, 表现出一定的随机性, 如 11 月和 6 月分别发生了强降水事 件, 降水量均接近 $50 \mathrm{~mm}$ (图 3). 从以上对比来看, 监测年内湖区降水特征与阿拉善右旗多年平均降水特征 差异明显. 但是, 如果以本次监测时段近似代表 2012 年, 并结合王乃昂等在 2010 和 2011 年的监测结果 ${ }^{[33]}$, 则湖区近 3 年的平均降水量约为 $114.6 \mathrm{~mm}$, 十分接近阿拉善右旗多年平均值, 这说明 $2010 、 2011$ 年为相对 贫水年, 2012 年为相对丰水年. 总体上看, 苏木吉林湖区降水量年际变化大, 季节变化不均匀, 多年平均降水 量与阿拉善右旗具有一致性.

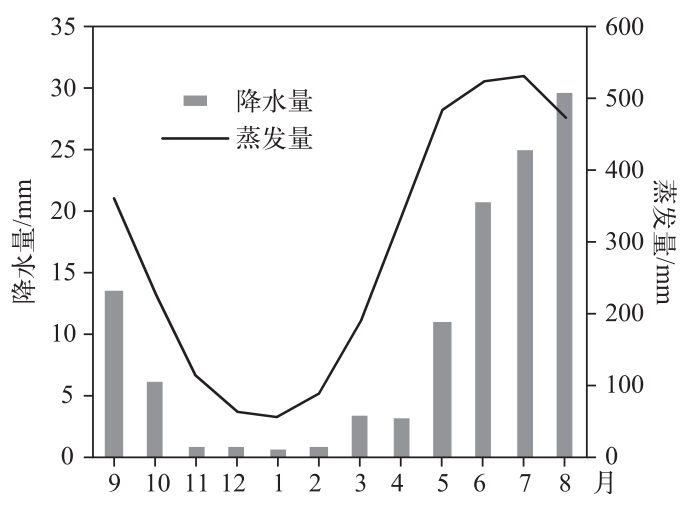

图 2 阿拉善右旗多年平均降水量和蒸发量曲线

Fig.2 The curves of the average precipitation and evaporation in Alxa Youqi

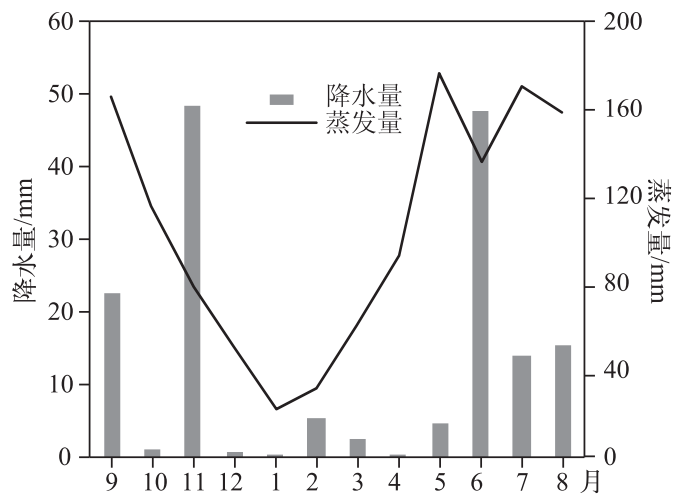

图 3 苏木吉林湖区降水量和蒸发量曲线

Fig. 3 The curve of the precipitation and evaporation in Sumu Jaran lakes area

湖区蒸发量在季节分配上同样呈夏季高、冬季低, 强降水事件对蒸发曲线造成扰动, 但扰动程度有限, 如 6 月连续的阴雨天气使该月蒸发量比相邻月份均偏低, 11 月虽然也发生了强降水事件,但由于该月气温 低、日照时间短, 本身蒸发量仅有 70 $80 \mathrm{~mm}$, 阴雨天气造成的蒸发量降低现象并不明显(图 3). 总体上, 湖 
区蒸发量的季节变化与阿拉善右旗规律基本一致, 但全年蒸发量仅 $1261 \mathrm{~mm}$,远小于阿拉善右旗气象站多 年平均值 $(3452 \mathrm{~mm}$ ). 因此推测造成年蒸发量巨大差异的主要原因可能有 2 个: 首先, 蒸发表面空气流动速 度是影响蒸发的重要因素, 巴丹吉林沙漠的湖泊基本都处于高大沙山的包围之中, 仿佛位于一个巨大的避 风坑的底部, 湖面风速远小于沙山顶部的风速; 其次, 众多学者研究发现, 水体盐度与蒸发量呈负相关关系, 并有学者指出可能是负指数关系 ${ }^{[38]}$, 在巴丹吉林沙漠水化学性质已知的湖泊中, 超过一半的湖泊矿化度大 于 $35 \mathrm{~g} / \mathrm{L}$, 最高可达 $400 \mathrm{~g} / \mathrm{L}$, 因此这些咸水湖的蒸发具有明显的盐度效应 ${ }^{[39-40]}$. 本研究监测蒸发量时, 蒸发 皿安装于湖心位置, 蒸发血内的水取自湖水且定期加人淡水以维持盐度与湖水一致, 较好地排除了由于忽 略这 2 个因素而造成的误差, 因而获得的蒸发量更加真实.

\section{2 水位}

利用 BaroDiver 进行气压校正后得到的水位动态数据如图 4, 湖水和地下水位均呈现出正弦曲线形态, 水位变化趋势一致, 在 4 月达到峰值, 11 月降到波谷, 湖水位变幅 $22 \mathrm{~cm}$, 地下水位变幅 $18 \mathrm{~cm}$, 两者水位差约 $1.8 \mathrm{~m}$. 湖水位曲线在 2 月 10 日前后出现陡然降低的异常情况, 这是当时气温达到最低点, 湖水发生冻结造 成的.
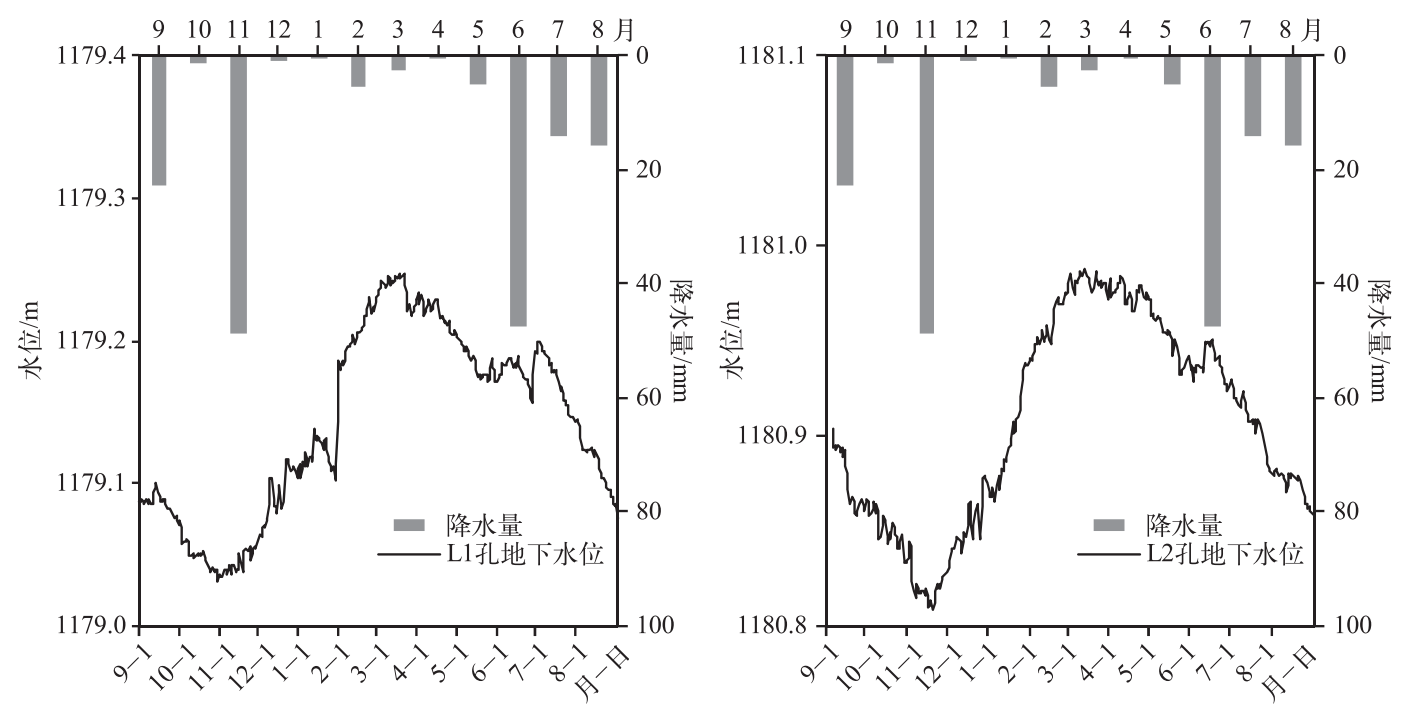

图 4 苏木吉林湖区湖水与地下水水位动态曲线

Fig.4 The curves of the groundwater level and lake level in Sumu Jaran lakes area

\section{3 数据分析}

2.3.1 降水与蒸发的均衡巴丹吉林沙漠湖泊群地区沙山林立, 高大沙山往往成为地表分水岭, 这样每 1 个 (或 2 个) 湖泊与将其围绕的数个沙山就会构成相对独立的水文地质单元. 苏木吉林湖区由两个湖泊及周围 的沙山组成 (图 1), 多年水位比较稳定, 假设湖泊与深层地下水没有水量交换, 则降水人渗是湖区唯一的地 下水来源, 这样湖区的水均衡表示为:

$$
P_{\mathrm{a}} \cdot A_{\text {湖 }}+\alpha \cdot P_{\mathrm{a}} \cdot A_{\text {沙 }}=E_{\mathrm{a}} \cdot A_{\text {湖 }}
$$

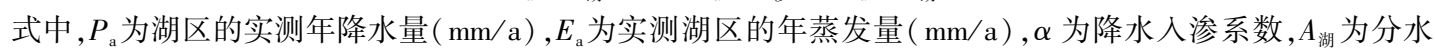

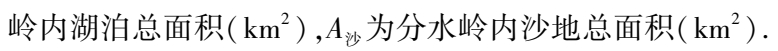

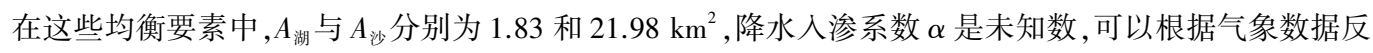
算出来. 根据上文对气象数据的分析, 湖区多年平均降水规律与阿拉善右旗一致,因此 $P_{\mathrm{a}}$ 取 $115.8 \mathrm{~mm}$. 湖区 年蒸发量仅有 1 年的监测数据, 由该数据可求出湖区蒸发量相对于阿拉善右旗的折算系数约为 0.365 (由 $1261 \mathrm{~mm} / 3452 \mathrm{~mm}$ 得到), 另据阿拉善右旗气象站数据, 1978- 2000 年期间年蒸发量变化区间为 3162 3803 $\mathrm{mm}$, 乘以折算系数可推算出苏木吉林湖区年蒸发量的变化区间, 即 $E_{\mathrm{a}}$ 在 $1155 \sim 1389 \mathrm{~mm}$ 之间. 
根据《水文地质手册》, 砂性土的人渗系数一般在 $0.05 \sim 0.30$ 之间 ${ }^{[41]}$, 本文计算出的降水人渗系数 $\alpha$ 为 0.75 0.92, 明显大于这个区间, 考虑到蒸发量的计算中还忽略了地下水浅埋区的贡献, 则 $\alpha$ 实际值比公式 (1) 的计算值还要大, 这与水文地质经验并不相符. 因此, 从降水与蒸发的均衡关系看, 单依靠湖区的降水人 渗,难以维持湖泊的蒸发消耗,有可能存在深层地下水的补给.

2.3.2 降水与水位的关系 地下水的补给和排泄共同作用,控制着地下水储存量的变化,表现为湖水位和地 下水位的波动.湖水位和地下水位在宏观上呈现正弦形态, 即 4-11 月逐渐降低, 11-4 月逐渐升高, 这种较 稳定的形态与降水事件的随机性形成鲜明的反差:超过 $60 \%$ 的降水量发生在 6 和 11 月, 但水位既没有在这 2 个月份出现波峰, 也没有在降水量最小的 1 月份降到波谷, 而且强降水事件对水位曲线造成的扰动十分有 限, 如 6 月的强降水仅表现为水位下降的暂缓或轻微上升, 11 月的强降水虽然伴随着水位的上升, 但却无法 解释之后几乎没有降水的 12-4 月之间的水位上升现象, 也就是说, 11 月的强降水并不是之后地下水位持 续上涨的根本原因, 除了这 2 个月份的强降水, 水位曲线对其它月份的降水事件几乎没有反应(图 4). 这些 现象指示, 降水不仅不是唯一补给源, 而且不是主要补给源, 可能存在一个更加充足和稳定的补给源维持着 水位的正弦形态. 因此,有理由推测湖泊接受了深层地下水的补给.

\section{3 模拟结果与分析}

上文基于对气象和水位监测数据的分析, 提出了湖泊水分补给的一种可能机制, 即接受降水和深层地 下水补给, 以蒸发的形式排泄. 为了验证这个推测是否合理并进行定量分析, 作者收集了研究区水文地质资 料,在此基础上建立苏木吉林湖区地下水流动模型.

\section{1 水文地质概念模型}

3.1 .1 含水层结构 $1980 \mathrm{~s}$ 原地质矿产部曾在研究区进行过 $1: 250000$ 水文地质普查, 根据区域水文地质普查 报告一一雅布赖盐场幅 ${ }^{[42]}$ 的资料和当地民井提供的信息, 苏木吉林湖区的地下水主要赋存在以粉细砂和中 粗砂为主的更新统湖积砂层中, 含水层中发育多个由湖积亚砂土、亚黏土组成的弱透水夹层, 多呈水平发 育, 其中最浅的位于湖底, 厚度一般不超过 $10 \mathrm{~m}$, 构成承压含水层顶板, 湖底可见一些泉眼(雅布赖盐场幅报 告中称为 “天窗” ), 深层承压水以泉水和越流的方式向上补给, 承压含水层厚度至少 $30 \mathrm{~m}$ 以上, 该层中的黏 性土夹层并不连续,多呈透镜体状,隔水底板由第三系泥质碎屑岩构成.

根据以上特征, 将含水层在垂向上划分为 3 层:第一层为第四系风积砂、晚更新世湖积粉细砂、中粗砂 构成的潜水含水层; 第二层为晚更新世湖积亚砂土、亚黏土构成的弱透水层, 作为承压含水层顶板; 第三层 为早中更新世湖积砂层与黏土透镜体构成的承压含水层 ( 图 5 ).

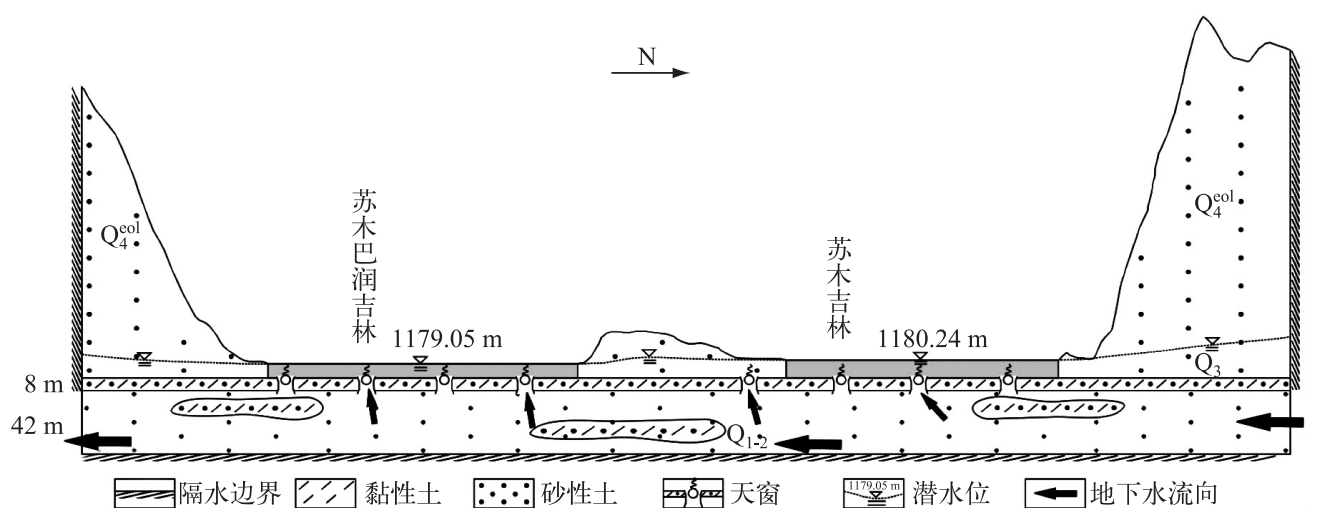

图 5 苏木吉林湖区水文地质概念模型剖面

Fig.5 Hydrogeological profile of the conceptual model in Sumu Jaran lakes area

3.1 .2 边界条件 湖区周围由沙山构成的天然分水岭可以作为潜水含水层的侧向隔水边界 (图 1), 顶部接受 大气降水人渗, 湖面和地下水浅埋区存在湖水和地下水蒸发,底部为第三系基岩基底构成的隔水边界, 承压 
含水层接受侧向径流补给和排泄,并向上补给潜水含水层.

3.1.3 地下水的补给排泄大气降水一部分直接补给湖泊, 另一部分通过沙层人渗后补给湖泊, 湖区多年平 均降水量约为 $115.8 \mathrm{~mm}$. 湖面和地下水浅埋区发生地下水蒸发, 湖面年蒸发量取本次监测值 $1261 \mathrm{~mm}$. 对于 深层承压水, 经同一时间内的高精度 GPS 测量知, 南湖湖面高程为 $1179.05 \mathrm{~m}$, 北湖湖面高程为 $1180.24 \mathrm{~m}$, 推测深层承压水有由北向南流动的趋势, 但侧向流人流出量不易确定. 根据雅布赖盐场幅报告中描述的补 给特征, 可将承压含水层近似处理为定水头边界, 承压水头高出湖面约 $3 \sim 5 \mathrm{~m}$, 这样可以由模型自行运算出 侧向流人流出量. 需要注意的是, 湖底地下水垂向运动强烈, 弱透水层在承压水头的压力下出现破裂, 形成 上文提到的“天窗” 泉, 经实地调查, “天窗” 泉在湖底和地下水埋深较浅的洼地发育十分普遍, 本次研究在 监测水位时, 设计 L2 孔的目标是监测深层地下水的水头, 从监测结果来看, 其与湖水具有几乎一致的变化 规律, 说明这些地区的承压水头并非定值. 因此, 在将第三层设为定水头时, 需将湖泊和两湖之间洼地以下 的第三层部分处理为自由水头.

\section{2 地下水流动三维数值模型}

3.2.1 模型剖分与初始流场 本次建模采用 GMS (Groundwater Modeling System) 软件, 地下水模型采用嵌人 到 GMS 中的 Modflow 程序包, 该程序包是目前国际上最为广泛采用的地下水有限差分模拟程序. 模型在水 平方向上剖分为 $70 \mathrm{~m} \times 80 \mathrm{~m}$ 的矩形单元, 湖泊周边水力梯度较大, 加密为 $35 \mathrm{~m} \times 40 \mathrm{~m}$ 的单元格. 模型的模拟 目标是重现湖区地下水流场的季节动态变化, 需要建立非稳定流模型, 其初始流场需要通过建立稳定流模 型来计算得到. 输人湖区多年平均降水和蒸发数据, 以湖区 4 口民井、2 个监测孔、 1 个有水洼地 ( 位置见图 7) 的水位作为稳定流模拟的验证依据,计算出的流场作为非稳定流模型的初始流场.

3.2 .2 水文地质参数 水文地质参数分区在模 型层划分的基础上进行, 主要参数包括渗透系 数、给水度、降水入渗系数和地下水蒸发极限 埋深. 第一层为渗透性较强的第四系砂层, 第 二层为渗透性较差的黏性土弱透水层, 第三层 承压含水层为砂层夹黏土透镜体, 渗透性能介 于前两者之间,分区及初始取值范围符合水文 地质规律 (表 2) ${ }^{[41-42]}$. 根据前人对沙性土垂向 渗透性的研究, 初始垂向渗透系数设为水平渗 透系数的 $1 / 100 \sim 1 / 10^{[43]}$. 本研究区尚无地下 水蒸发极限埋深的实验数据, 胡顺军等 ${ }^{[39]}$ 在塔 克拉玛干沙漠的实验测得当地地下水蒸发极
表 2 模型参数初始取值范围及校正结果

Tab.2 The initial value ranges and the optimized parameters of the model

\begin{tabular}{lcc}
\hline 参数 & 初始取值范围 & 校正结果 \\
\hline 潜水含水层渗透系数 $K_{1} /(\mathrm{m} / \mathrm{d})$ & $1.5 \sim 10.0$ & 5 \\
弱透水层渗透系数 $K_{2} /(\mathrm{m} / \mathrm{d})$ & $0.05 \sim 0.25$ & 1 \\
承压含水层渗透系数 $K_{3} /(\mathrm{m} / \mathrm{d})$ & $0.5 \sim 5.0$ & 3 \\
降水人渗系数 & $0.1 \sim 0.3$ & 0.15 \\
给水度 & $0.2 \sim 0.3$ & 0.3 \\
水平与垂向渗透系数比值 $K_{\mathrm{h}} / K_{\mathrm{v}}$ & $10 \sim 100$ & 100 \\
承压含水层定水头 $/ \mathrm{m}$ & $1183 \sim 1185$ & 1184.8 \\
\hline
\end{tabular}
限埋深为 $3.89 \mathrm{~m}$, 本研究区水文地质条件与之相似, 因此采用该经验参数.

3.2.3 湖泊的处理 地下水数值模拟中处理湖泊的方法很多, 主要有定水头法 (specified head nodes)、drain 模块、reservoir 模块、强渗漏单元法 (high hydraulic conductivity notes) 等. 本次研究中需要知道湖水位的变化 和湖水与地下水的交换量, 只有强渗漏单元法满足要求. 该方法是把湖泊作为含水层的一部分, 将湖泊所在 区域设置为具有高渗透率的单元格 (大致为周围岩土体渗透系数的 1000 倍), 给水度设为 $1^{[44]}$.

3.2.4 模型识别与验证稳定流模型的校正采用 “试错法”, 主要调整了渗透系数和给水度, 校正后的水文地 质参数取值见表 2. Nash-Sutcliffe 效率系数 (NSE) 常被用来评价水文模型的模拟优度,其计算公式为:

$$
N S E=1-\sum_{i=1}^{N}\left(S_{i}-O_{i}\right)^{2} / \sum_{i=1}^{N}\left(O_{i}-\bar{O}\right)^{2}
$$

式中, $S_{i}$ 为模拟值, $O_{i}$ 为实测值, $\bar{O}$ 为所有实测值的平均值. $N S E$ 的取值范围为 $-\infty$ 到 1 , 越接近 1 说明模拟结 果越可信, 本次稳定流模拟的 NSE 为 0.94 , 模拟结果良好 (图 6).

湖区的水位呈漏斗状分布, 从分水岭到湖泊, 水位从接近 $1185 \mathrm{~m}$ 逐渐降低至 $1179 \mathrm{~m}$, 水力梯度也呈现 渐变的规律, 越靠近湖泊的地区水力梯度越大, 湖边的水力梯度大约 $1 / 100$, 而分水岭处则不足 $1 / 1000$, 湖泊 由于蒸发成为漏斗最低处的汇水区. 在北部的洼地位置存在水位为 $1184 \mathrm{~m}$ 的封闭等水头线, 在东部的低洼 


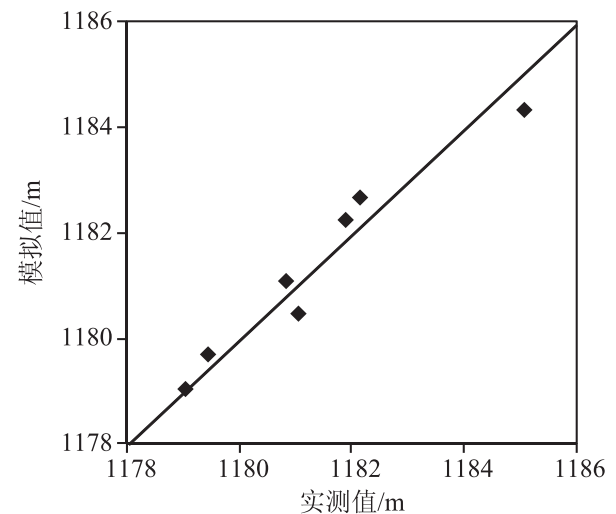

图 6 稳定流模拟水位与实测水位对比

Fig. 6 Comparison of computed and observed groundwater levels based on the steady model
地带, 1184.6 1184.7 $\mathrm{m}$ 之间也存在一个圈闭的等水头线, 经实地考察这 2 个地方都是小型有水洼地. 2 个湖泊之间 的地带存在一个潜水面的分水岭, 最高水位约 $1181.6 \mathrm{~m}$, 这 说明 2 个湖泊之间不存在侧向水量交换. 承压含水层的水 头为 $1184.8 \mathrm{~m}$, 说明湖区内约 $2 / 3$ 的面积接受深层地下水 向上的越流补给 (图 7).

非稳定流模型的模拟期为 9 月 1 日至次年 8 月 31 日， 时间步长为 1 个月, 模型需要经历多个模拟期方能达到稳 定, 即将每个模拟期的期末流场作为下一个模拟期的初始 流场反复模拟, 直至一个模拟期的始末水位相差不超过 $0.01 \mathrm{~m}$ 时, 可认为该模拟期内的地下水动态流场可代表湖 区多年平均动态流场.

非稳定流模型计算出的 L1 孔和 L2 孔季节动态水位见 图 8. 由于缺乏地下水位的多年平均实测数据, 以实测 2012 年 9 月 1 日 2013 年 8 月 31 日的两孔水位数据与模拟水

位作对比. L1 孔与 L2 孔的模拟水位均呈正弦曲线形态, 与实测水位变化趋势吻合, 波峰出现的时间和高度 基本一致; 波谷处存在一定的差距,实测水位偏低且波谷出现时间偏晚,推测是由于前一年降水偏少 (2011 年为贫水年, 年降水量仅 $75 \mathrm{~mm}^{[35]}$ ) 及 2012 年雨季偏晚 (最大降水量出现在 11 月,多年平均最大降水量出 现在 8 月, 见图 2 和图 3 ) 造成的. 总体上, 模型较好地模拟了湖区水位的空间分布和季节动态变化, 能够合 理地解释在观测年气象条件下波谷水位偏低及滞后的现象, 因此以该模型进行水均衡分析具有合理性.

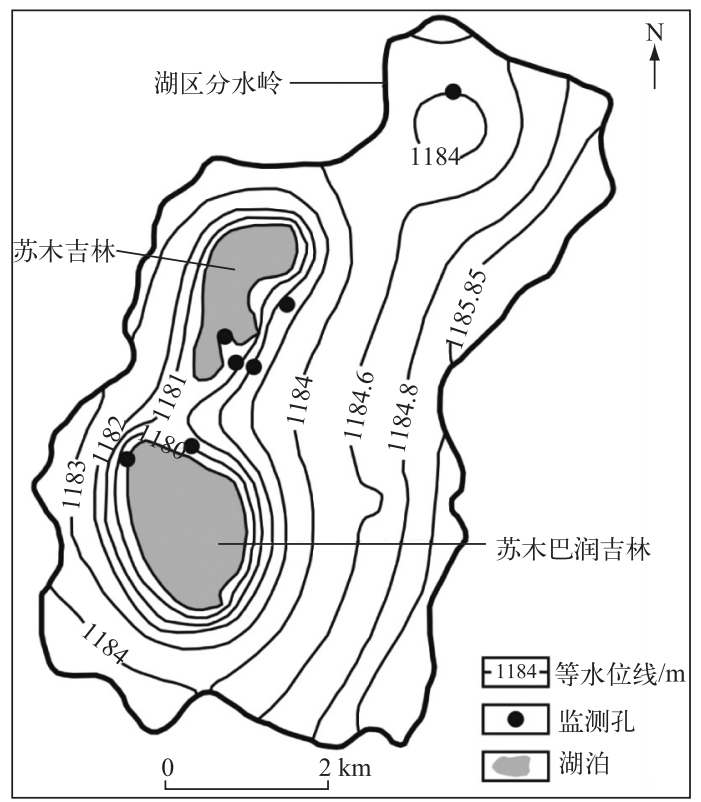

图 7 苏木吉林湖区等水位线

Fig.7 The contour map of groundwater level in Sumu Jaran lakes area 


\section{4 讨论}

\section{1 湖泊水分补给机制}

湖泊多年平均降水补给量为 $1721 \mathrm{~m}^{3} / \mathrm{d}$,多年平 均越流补给量为 $9899 \mathrm{~m}^{3} / \mathrm{d}$, 分别占 $13 \%$ 和 $87 \%$, 总 补给量 $11620 \mathrm{~m}^{3} / \mathrm{d}$. 承压水越流补给量年内动态稳 定,月补给量在其平均值上下 $1.5 \%$ 内浮动, 降水入渗 补给量则呈现出明显的季节动态变化, 8 月份最高 $\left(5208 \mathrm{~m}^{3} / \mathrm{d}\right)$, 占当月总补给量的 $34 \%, 1$ 月份降到最 低 $\left(116 \mathrm{~m}^{3} / \mathrm{d}\right)$, 此时越流补给量为 $9791 \mathrm{~m}^{3} / \mathrm{d}$, 几乎 所有的湖水补给量都来自深层承压水 (表 3).

湖泊的 2 种补给方式中,降水补给量与越流补给 量相比基数较小,因此总补给量在后者的控制下年内 变幅相对较小,约 $5000 \mathrm{~m}^{3} / \mathrm{d}$; 蒸发是湖泊唯一的排 泄方式,受其控制, 总排泄量的年内变幅较大, 高达约 $20000 \mathrm{~m}^{3} / \mathrm{d}$. 补给和排泄的共同作用下, 湖泊净补给 量呈现正弦曲线形态, 11-4 月为正值, 4-11 月为负 值, 这个规律解释了湖水位和地下水位峰谷值出现的 时间 (图 9).

\section{2 沙漠是否需要外部水源}

除降水外,湖泊需要来自承压水越流的额外补 给. 从目前研究来看, 其来源有两种可能: 首先, 沙漠 边缘山区降水下渗后向地势更低的沙漠腹地流动形 成具有承压性的地下径流 ${ }^{[17,33,42,45-46]}$; 其次, 可能存在 深部断裂将外部水源导人沙漠腹地 ${ }^{[4,14,18-19,21-22,47-48]}$. 如果我们知道这两种补给方式的规模, 就可以对承压 水越流补给的水源进行初步判断.

沙漠内湖泊总面积大约为 $17 \sim 19 \mathrm{~km}^{2[33]}$, 约为苏 木吉林两湖面积 (约 $1.83 \mathrm{~km}^{2}$ ) 的 9.7 倍, 如果近似认 为沙漠总湖域面积 (即沙山-湖泊水文地质单元的面 积) 也为苏木吉林湖域面积 (图 1 中小图黑线圈闭的 面积) 的 9.7 倍, 则整个沙漠维持湖泊群需要的承压 水越流量大约为 $9.6 \times 10^{4} \mathrm{~m}^{3} / \mathrm{d}$. 王旭升等 ${ }^{[33]}$ 估算的沙 漠东南部雅布赖山地区降水人渗形成的区域地下水 侧向径流向沙漠腹地的补给量约为 $(5.5 \sim 19.2) \times 10^{4}$

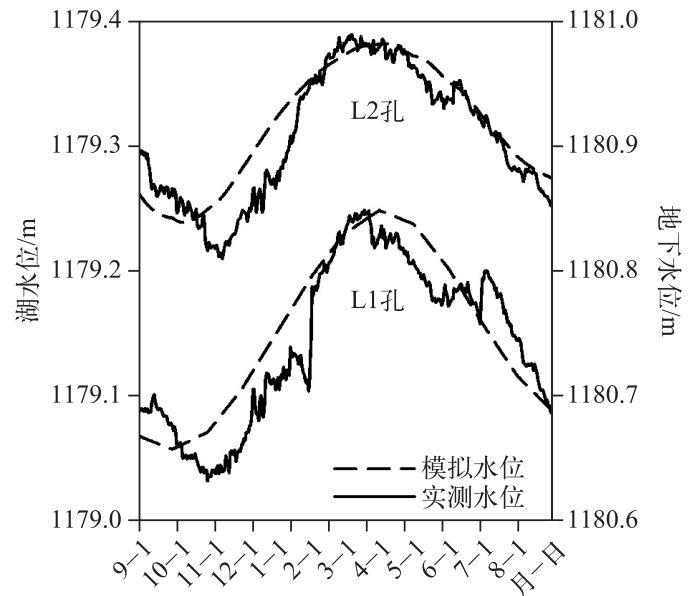

图 8 非稳定流模拟水位与实测水位曲线

Fig. 8 Comparison of computed and observed groundwater level based on the transient model

表 3 苏木吉林湖区湖泊水分补给方式及补给量

Tab.3 The water supply mode and recharge of Sumu Jaran lakes

\begin{tabular}{|c|c|c|c|c|}
\hline \multirow[b]{2}{*}{ 时间 } & \multicolumn{2}{|c|}{ 降水补给 } & \multicolumn{2}{|c|}{ 承压水越流补给 } \\
\hline & $\begin{array}{l}\text { 补给量/ } \\
\left(\mathrm{m}^{3} / \mathrm{d}\right)\end{array}$ & 占比 & $\begin{array}{l}\text { 补给量/ } \\
\left(\mathrm{m}^{3} / \mathrm{d}\right)\end{array}$ & 占比 \\
\hline 9 月 & 2474 & $20 \%$ & 9942 & $80 \%$ \\
\hline 10 月 & 1085 & $10 \%$ & 9939 & $90 \%$ \\
\hline 11 月 & 174 & $2 \%$ & 9907 & $98 \%$ \\
\hline 12 月 & 151 & $2 \%$ & 9844 & $98 \%$ \\
\hline 1 月 & 116 & $1 \%$ & 9791 & $99 \%$ \\
\hline 2 月 & 179 & $2 \%$ & 9763 & $98 \%$ \\
\hline 3 月 & 581 & $6 \%$ & 9770 & $94 \%$ \\
\hline 4 月 & 574 & $5 \%$ & 9869 & $95 \%$ \\
\hline 5 月 & 1926 & $16 \%$ & 9983 & $84 \%$ \\
\hline 6 月 & 3777 & $27 \%$ & 10016 & $71 \%$ \\
\hline 7月 & 4411 & $31 \%$ & 10022 & $69 \%$ \\
\hline 8 月 & 5208 & $34 \%$ & 9939 & $66 \%$ \\
\hline
\end{tabular}
$\mathrm{m}^{3} / \mathrm{d}$, 张竞等 ${ }^{[45]}$ 对沙漠宏观流场的研究发现除了雅布赖山, 沙漠南侧北大山及东侧宗乃山的地下水也有向 沙漠腹地湖泊群补给的趋势, 总侧向补给量可达 $(16.7 \sim 53.9) \times 10^{4} \mathrm{~m}^{3} / \mathrm{d}$, 如果这些数据可靠, 那么深层承压 水侧向径流不仅能够抵消湖泊群的蒸发, 还将有盈余量继续向地势更低的古日乃湖、拐子湖和额济纳旗等 地区排泄, 这符合目前对巴丹吉林沙漠地下水流向的认识 ${ }^{[46]}$. 也就是说, 湖区接受的承压水越流补给可能 主要来自沙漠周边山区降水下渗形成的侧向径流, 未见明显的水量亏空需要断裂导水来弥补.

\section{5 结论与建议}

本次监测和模拟研究补充了沙漠腹地的气象和水位资料, 通过建立地下水流动模型较好地重现了湖区 地下水位的季节动态变化, 并基于模型进行了水均衡分析, 定量揭示了沙漠腹地典型沙山一湖泊水文地质 


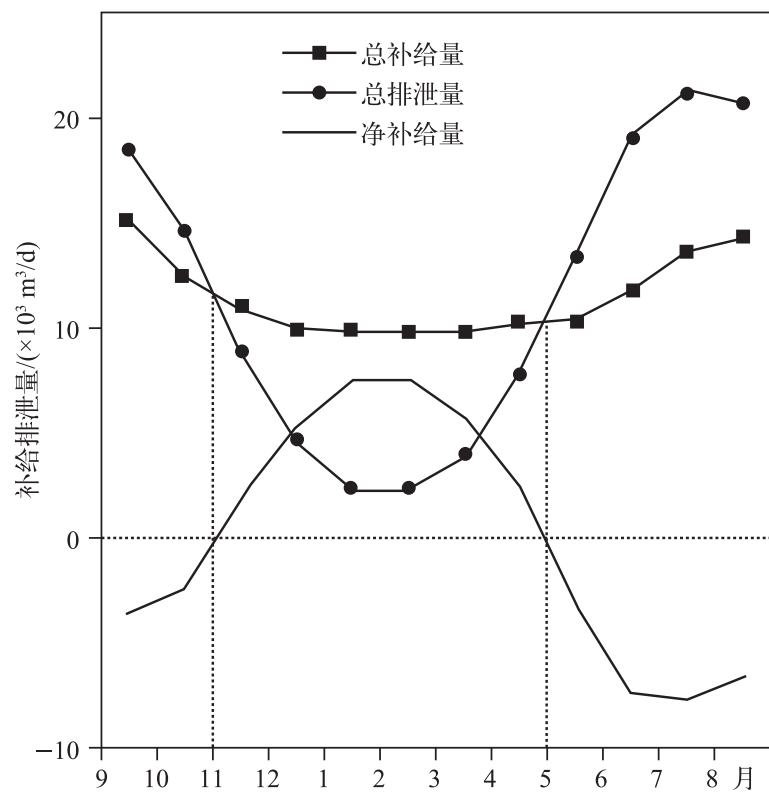

图 9 苏木吉林湖区湖泊补给量和排泄量动态曲线

Fig.9 Dynamic curve of the recharge and discharge of the Sumu Jaran lakes area

单元地下水补给和排泄的动态特征, 研究结果对巴丹吉林沙漠区域地下水资源的分析和合理利用有重要意 义. 主要结论如下:

1) 苏木吉林湖区降水量年际变化大,季节变化不均匀,但多年平均降雨量与沙漠南部阿拉善右旗一致. 年蒸发量为 $1261 \mathrm{~mm}$, 远小于阿拉善右旗多年平均值, 推测湖面所处的低洼地形和湖水高矿化度带来的盐度 效应是蒸发量偏小的原因. 湖区降水人渗补给量难以平衡湖泊蒸发量.

2) 湖水位和地下水位均呈正弦曲线形态, 水位的波峰和波谷分别出现在 4 月和 11 月,湖水位变幅 22 $\mathrm{cm}$,地下水位变幅 $18 \mathrm{~cm}$. 水位曲线与降水的关系显示降水不是湖泊的主要补给源.

3) 基于模型的水均衡计算显示, 苏木吉林湖区湖泊主要接受当地降水和深层承压水越流补给, 多年平 均总补给量为 $11620 \mathrm{~m}^{3} / \mathrm{d}$, 其中当地降水和越流补给分别约占 $13 \%$ 和 $87 \%$, 降水补给量夏季高、冬季低, 承 压水越流补给量季节变化不明显.

4) 承压水越流补给量可能主要来源于沙漠东南边缘山区降水, 未见明显的水量亏空需要断裂导水来 弥补.

建议: 本文在完成监测和模拟研究的基础上, 通过对比湖泊蒸发所需的承压水越流补给量和沙漠周边 山区降水人渗可提供的承压水侧向径流量, 判断了沙漠是否需要断裂导水补给, 这是一种间接的判断方法. 目前受限于对研究区水文地质条件的认识, 还难以找到是否存在断裂导水的直接证据. 应当继续开展钻探、 物探等工作,加强对深部水文地质条件的探索.

\section{6 参考文献}

[ 1 ] Ren Wei, Jin Sheng. Applying audio-magnetelluric method to the study of megadune structure and formation in Badain Jare Desert, Inner Mongolia. Geoscience, 2011, 25(6) : 1167-1173. [任伟, 金胜. 应用音频大地电磁法探测内蒙古巴丹吉 林高大沙山结构及成因. 现代地质, 2011, 25(6): 1167-1173.]

[ 2 ] Huang Tianming, Pang Zhonghe. Groundwater recharge in Badain Jaran Desert and Gurinai Oasis based on environmental tracers. Geoscience, 2007, 21(4): 624-631. [ 黄天明, 庞忠和. 应用环境示踪剂探讨巴丹吉林沙漠及古日乃绿洲地 下水补给. 现代地质, 2007, 21(4): 624-631.]

[ 3 ] Li Mingsen. Visit the Badain Jaran Desert. Chinese Journal of Nature, 2007, 29(5) : 300-302. [李明森. 探访巴丹吉林 
沙漠. 自然杂志, 2007, 29(5) : 300-302.]

[ 4 ] Chen JS, Li L, Wang JY et al. Groundwater maintains dune landscape. Nature, 2004, 432(7016) : 459-460.

[ 5 ] Dong ZB, Qian GQ, Lü P et al. Investigation of the sand sea with the tallest dunes on Earth: China's Badain Jaran Sand Sea. Earth-Science Reviews, 2013, 120(120) : 20-39.

[ 6 ] Wang Tao. Formation and evolution of Badain Jirin Sandy Desert, China. Journal of Desert Research, 1990, 10(1) : 2940. [王涛. 巴丹吉林沙漠形成演变的若干问题. 中国沙漠，1990，10(1) : 29-40.]

[ 7 ] Dong ZB, Wang T, Wang XM. Geomorphology of the mega-dunes in the Badain Jaran Desert. Geomorphology, 2004, 60 $(1 / 2): 191-203$.

[ 8 ] Edmunds WM, Ma JZ, Aeschbach HW et al. Groundwater recharge history and hydrogeochemical evolution in the Minqin Basin, North West China. Applied Geochemistry, 2006, 21(12) : 2148-2170.

[ 9 ] Gates JB, Edmunds WM, Ma JZ et al. Estimating groundwater recharge in a cold desert environment in Northern China using chloride. Hydrogeology Journal, 2008, 16(5) : 893-910.

[ 10] Ma JZ, Ding Z, Gates JB et al. Chloride and the environmental isotopes as the indicators of the groundwater recharge in the Gobi Desert, northwest China. Environmental Geology, 2008, 55(7) : 1407-1419.

[11] Ma JZ, Edmunds WM. Groundwater and lake evolution in the Badain Jaran Desert ecosystem, Inner Mongolia. Hydrogeology Journal, 2006, 14(7): 1231-1243.

[ 12] Ma JZ, Edmunds WM, He J et al. A 2000 year geochemical record of palaeoclimate and hydrology derived from dune sand moisture. Palaeogeography, Palaeoclimatology, Palaeoecology, 2009, 276(1-4) : 38-46.

[13] Ma Jinzhu, Huang Tianming, Ding Zhenyu et al. Environmental isotopes as the indicators of the groundwater recharge in the south Badain Jaran Desert. Advances in Earth Science, 2007, 22(9): 922-930. [马金珠, 黄天明, 丁贞玉等. 同位 素指示的巴丹吉林沙漠南缘地下水补给来源. 地球科学进展, 2007, 22(9): 922-930.]

[14] Ding Hongwei, Wang Guiling. Study on the formation mechanism of the lakes in the Badain Jaran Desert. Arid Zone Research, 2007, 24(1) : 1-7. [丁宏伟, 王贵玲. 巴丹吉林沙漠湖泊形成的机理分析. 干旱区研究, 2007, 24(1)： 1-7. ]

[15] Wu Yanqing, Mu Fuqiang, He Yixian et al. Analysis of the transformation path between stream flow and groundwater from Dingxin to Shaomaying in Hei River, Catchment West China. Journal of Glaciology and Geocryology, 2000, 22(1) : 7377. [仵彦卿, 慕富强, 贺益贤等. 河西走廊黑河鼎新至哨马营段河水与地下水转化途径分析. 冰川冻土, 2000,22 (1) : 73-77.]

[16] Wu Yanqing, Zhang Yinghua, Wen Xiaohu et al eds. Simulation on hydrologic cycle and water resource in Hei River basin in northwest China. Beijing: Science Press, 2010: 101-131. [仵彦卿, 张应华, 温小虎等. 中国西北黑河流域水文循 环与水资源模拟. 北京: 科学出版社, 2010: 101-131.]

[17] Sun Deqin, Tian Ronghe, Li Zhongxue et al. Geological and hydrogeological survey report in western Inner Mongolia Plateau(1: 500000). China Geology Department, 1961: 15-41. [孙德钦, 田荣和, 李忠学等. 内蒙古高原西部综合地 质一一水文地质普查报告书 $(1: 50$ 万). 原地质矿产部, 1961: 15-41.]

[18] Chen Jiansheng, Wang Jiyang, Zhao Xia et al. Study of groundwater supply of the confined aquifers in the Ejin Basin based on isotopic methods. Geological Review, 2004, 50(6): 649-658. [陈建生, 汪集昒, 赵霞等. 用同位素方法研究额济 纳盆地承压含水层地下水的补给. 地质论评, 2004, 50(6): 649-658.]

[19] Chen Jiansheng, Zhao Xia, Sheng Xuefen et al. Geochemical information indicating the water recharge to lakes and immovable megadunes in the Badain Jaran Desert. Acta Geologica Sinica(English Edition), 2005, 79(4) : 541-546.

[20] Chen FH, Wei W, Holmes JA et al. A mid-Holocene drought interval as evidenced by lake desiccation in the Alashan Plateau, Inner Mongolia, China. Chinese Science Bulletin, 2003, 48(14) : 1401-1410.

[21] Chen Jiansheng, Fan Zhechao, Wang Jiyang et al. Isotope methods for studying the replenishment of the lakes and downstream groundwater in the Badain Jaran Desert. Acta Geoscientica Sinica, 2003, 24(6): 497-504. [陈建生, 凡哲超, 汪 集旸等. 巴丹吉林沙漠湖泊及其下游地下水同位素分析. 地球学报, 2003, 24(6)：497-504.]

[22] Chen Jiansheng, Zhao Xia, Wang Jiyang et al. Meaning of the discovery of lacustrine tufa and root-shaped nodule in Badain Jaran Desert for the study on lake recharge. Carsologica Sinica, 2004, 23(4): 277-282. [ 陈建生, 赵霞, 汪集旸 等. 巴丹吉林沙漠湖泊钙华与根状结核的发现对研究湖泊水补给的意义. 中国岩溶, 2004, 23(4): 277-282.]

[23] Zhao LJ, Xiao HL, Dong ZB et al. Origins of groundwater inferred from isotopic patterns of the Badain Jaran Desert, 
Northwestern China. Ground Water, 2012, 50(5) : 715-725.

[24] Shao Tianjie, Zhao Jingbo, Dong Zhibao. Water chemistry of the lakes and groundwater in the Badain Jaran Desert. Acta Geographica Sinica, 2011, 66(5) : 662-672. [ 邵天杰, 赵景波, 董治宝. 巴丹吉林沙漠湖泊及地下水化学特征. 地 理学报, 2011, 66( 5) : 662-672.]

[25] Zhang Hucai, Ming Qingzhong. The evolution of hydrology and lakes in the extreme arid west of China and the formation of the megadunes in the Badain Jaran Desert. Advances in Earth Science, 2006, 21(5): 532-538. [张虎才, 明庆忠. 中国 西北极端干旱区水文与湖泊演化及其巴丹吉林沙漠大型沙丘的形成. 地球科学进展, 2006, 21(5): 532-538. ]

[26] Zhang Huaan, Wang Naiang, Li Zhuolun et al. Features of hydrogen and oxygen isotopes in lakes and groundwater in southeast Badain Jaran Desert. Journal of Desert Research, 2011, 31(6): 1623-1629. [张华安, 王乃昂, 李卓仑等. 巴 丹吉林沙漠东南部湖泊和地下水的氢氧同位素特征. 中国沙漠, 2011, 31(6)：1623-1629.]

[27] Zhao Jingbo, Shao Tianjie, Hou Yule et al. Study on moisture content of sand layer and its origin in a mega-dune area in the Badain Jaran Desert. Journal of Natural Resources, 2011, 26(4) : 694-702. [赵景波, 邵天杰, 侯雨乐等. 巴丹吉 林沙漠高大沙山区沙层含水量与水分来源探讨. 自然资源学报, 2011, 26(4) : 694-702.]

[28] Liu Jiangang. Recharge mechanisms of lakes and groundwater in Badain Jaran Desert. Water Resources Protection, 2010,26 (2)：18-23. [刘建刚. 巴丹吉林沙漠湖泊和地下水补给机制. 水资源保护, 2010, 26(2): 18-23. ]

[29] Zhang Jin, Li Jintie, Li Yanfeng et al. The Cenozoic deformation of the Alxa Block in central Asia-Question on the northeastern extension of the Altyn Tagh Fault in Cenozoic Time. Acta Geologica Sinica, 2007, 81(11): 1481-1497. [张进, 李锦轶, 李彦峰等. 阿拉善地块新生代构造作用: 兼论阿尔金断裂新生代东向延伸问题. 地质学报, 2007,81 (11) : 1481-1497.]

[30] Yang Xiaoping. Water chemistry of the lakes in the Badain Jaran Desert and their Holocene evolutions. Quaternary Sciences, 2002, 22(2) : 97-104. [杨小平. 巴丹吉林沙漠腹地湖泊的水化学特征及其全新世以来的演变. 第四纪研 究, 2002, 22(2): 97-104.]

[31] Yang XP, Liu TS, Xiao HL. Landscape evolution and precipitation changes in the Badain Jaran Desert during the last 30, 000 years. Chinese Science Bulletin, 2000, 45(11): 1042-1047.

[32] Ma Nina, Yang Xiaoping. Environmental isotopes and water chemistery in the Badain Jaran Desert and in its southeastern adjacent areas, Inner Mongolia and their hydrological implications. Quaternary Sciences, 2008, 28(4): 702-712. [马妮 娜, 杨小平. 巴丹吉林沙漠及其东南边缘地区水化学和环境同位素特征及其水文学意义. 第四纪研究, 2008, 28 (4) : 702-707.]

[33] Wang Xusheng, Hu Xiaonong, Jin Xiaomei et al. Interactions between groundwater and lakes in Badain Jaran Desert. Earth Science Frontiers, 2014, 21(4): 91-99. [王旭升, 胡晓农, 金晓媚等. 巴丹吉林沙漠地下水与湖泊的相互作 用. 地学前缘, 2014, 21(4) : 91-99.]

[34] Lu Huiting. An investigation on water balance in the area of Sumujilin lakes in Badain Jaran Desert [Dissertation]. Beijing: China University of Geosciences (Beijing), 2014: 24-42. [卢会婷. 巴丹吉林沙漠苏木吉林湖区水分平衡研究 [ 学位 论文]. 北京: 中国地质大学 (北京), 2014: 24-42.]

[35] Wang Naiang, Ma Ning, Chen Hongbao et al. A preliminary study of precipitation characteristics in the hinterland of Badain Jaran Desert. Advances in Water Science, 2013, 24(2) : 153-160. [王乃昂, 马宁, 陈红宝等. 巴丹吉林沙漠腹地 降水特征的初步分析. 水科学进展, 2013, 24(2): 153-160.]

[36] Ma Ning. Observation of energy partitioning and lake evaporation in the Badain Jaran Desert [Dissertation]. Lanzhou: Lanzhou University, 2012: 59-60. [马宁. 巴丹吉林沙漠能量分配与湖泊蒸发量的观测研究 [学位论文]. 兰州: 兰 州大学, 2012: 59-60.]

[37] Yang XP, Ma NN, Dong JF et al. Recharge to the inter-dune lakes and Holocene climatic changes in the Badain Jaran Desert, western China. Quaternary Research, 2010, 73(1): 10-19.

[38] Qi Zexue. Study on the water evaporation salinity effect and the influencing factors[Dissertation]. Xi'an: Chang'an University, 2015: 35-47. [祁泽学. 水面蒸发盐度效应及影响因素研究 [学位论文]. 西安: 长安大学, 2015: 35-47.]

[39] Hu Shunjun, Lei Jiaqiang, Xu Xinwen et al. Theory analysis of evapotranspiration extinction depth of sandy phreatic in Taklimakan Desert. Chinese Science Bulletin, 2008, 53(s2): 107-111. [胡顺军, 雷加强, 徐新文等. 塔克拉玛干沙漠 风沙土潜水极限蒸发强度的理论分析. 科学通报, 2008, 53( s2) : 107-111.]

[40] Shen Shiping, Wang Naiang, Ma Ning et al. Study on the comparison of evaporation of saline water and fresh water and the 
influence factor. Symposium on natural geography and ecological security, 2012. [沈士平, 王乃昂, 马宁等. 巴丹吉林 沙漠咸-淡水蒸发量对比及其影响因素分析. 2012 自然地理学与生态安全学术研讨会, 2012.]

[41] Wang Min, Yin Yueping, Wen Dongguang et al eds. Handbook of hydrogeology (Second Edition). Beijing: Science Press, 2012: 680-683. [汪民，殷跃平，文冬光等. 水文地质手册(第二版). 北京: 科学出版社, 2012: 680-683. ]

[42] Sheng Baoyin, Li Jiabin, Zhang Zhe et al. Survey report of regional hydrogeology in China $(1: 200000)$ - Map of Yabrai saltworks. China Geology Department, 1982: 10-33. [绳宝印, 李嘉斌, 张哲等. 中华人民共和国区域水文地质普查 报告 $(1: 20$ 万)——雅布赖盐场幅. 原地质矿产部, 1982: 10-33. ]

[43] Deng Huisen. Study on the horizontal and vertical hydraulic conductivity of soil layers. Exploration of Science and Technolo$g y, 1992$, (4) : 19-20. [邓惠森. 岩土层垂向渗透系数与径向渗透系数. 勘察科学技术, 1992, (4) : 19-20.]

[44] Anderson MP, Hunt RJ, Krohelski JT et al. Using high hydraulic conductivity nodes to simulate seepage lakes. Ground Water, 2002, 40(2): 117-122.

[45] Zhang Jing, Wang Xusheng, Hu Xiaonong et al. The macro-characteristics of groundwater flow in the Badain Jaran Desert. Journal of Desert Research, 2015, 35(3): 1-10. [张竞, 王旭升, 胡晓农等. 巴丹吉林沙漠地下水流场的宏观特征. 中国沙漠, 2015, 35(3): 1-10.]

[46] Zhang Jing, Wang Xusheng, Jia Fengchao et al. New insights into the flow directions of groundwater in western Alxa, Inner Mongolia. Geoscience, 2015, 29(1) : 213-219. [张竞, 王旭升, 贾凤超等. 对内蒙古阿拉善西部地下水流向问题的 新认识. 现代地质, 2015, 29(1): 213-219.]

[47] Chen Jiansheng, Wang Jiyang. Study on the effect of the discovery of the underground reservoirs in the Badain Jaran Desert on water diversion plan in the west of China. Journal of Economics of Water Resources, 2004, 22(3): 28-32. [陈建生, 汪 集旸. 试论巴丹吉林沙漠地下水库的发现对西部调水计划的影响. 水利经济, 2004, 22(3): 28-32.]

[48] Chen Jiansheng, Zhao Xia, Sheng Xuefen et al. Research on the formation of the lakes group and sand dunes in Badain Jaran Desert. Chinese Science Bulletin, 2006, 51(23) : 2789-2796. [ 陈建生, 赵霞, 盛雪芬等. 巴丹吉林沙漠湖泊群与 沙山形成机理研究. 科学通报, 2006, 51(23): 2789-2796.] 